Research Paper:

\title{
Nurses' Perspectives on the Barriers and Facilitators of Pain Management in Hospitalized Patients
}

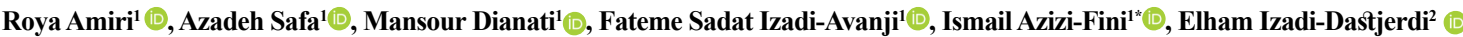

1. Trauma Nursing Research Center, Faculty of Nursing and Midwifery, Kashan University of Medical Sciences, Kashan, Iran

2. Department of Nursing, Faculty of Nursing and Midwifery, Isfahan University of Medical Sciences, Isfahan, Iran.

\begin{tabular}{|c|c|}
\hline \multirow{2}{*}{$\begin{array}{l}\text { Use vour device toscan } \\
\text { and read the article online }\end{array}$} & \\
\hline & Crtation: Amiri, R., et al. 2019. Nurses' Perspectives on the Barriers and Facilitators of Pain Management in Hospitalized \\
\hline 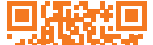 & Patients. Journal of Client-Centered Nursing Care, 5(3), pp. 193-202. https://doi.org/10.32598/JCCNC.5.3.193 \\
\hline 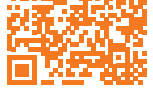 & doi) https://doi.org/10.32598/JCCNC.5.3.193 \\
\hline
\end{tabular}

\section{(1) (3)}

Article info:

Received: 05 Jan 2019

Accepted: 21 May 2019

Published: 01 Aug 2019

Keywords:

Pain, Pain management, Barriers, Facilitators,

Nurse

\begin{abstract}
A B S T RA C T
Background: Pain management is among the key tasks of nurses. Numerous studies have investigated the barriers and facilitators of pain management with conflicting results. The current study investigated the Iranian nurses' perspectives in terms of the barriers and facilitators of pain management in hospitalized patients.

Methods: This was a cross-sectional study. A total of 321 nurses working in a large general teaching hospital were recruited by the census method. A two-part, self-report questionnaire, including questions on nurses' characteristics and barriers and facilitators of pain management, was applied to collect data. The questionnaire was developed by researchers using a literature review. The questionaries' reliability was assessed through a test-retest with a correlation coefficient of 0.89. SPSS was used for statistical data analysis. Descriptive statistics (frequency, percentage, mean, and standard deviation) were applied to analyze the data.

Results: Insufficient nurse/patient ratio (Mean \pm SD: $3.31 \pm 0.87$ ), excessive demand for pain medications by the patients $(3.12 \pm 0.95)$, the spoken language difference between physician and patient (3.01 \pm 0.85$)$, the ignorance of pain as a priority in care (2.94 \pm 0.98$)$, and failure to precise pain assessment $(2.90 \pm 0.89)$ were determined by the nurses, as the main barriers to pain management, respectively. The studied nurses also perceived the attendance of in-service courses of pain management (3.39 \pm 0.63$)$, having sufficient pain management skills $(3.24 \pm 0.76)$, motivation for relieving the patient's pain $(3.24 \pm 0.81)$, effective nurse-physician relationship (3.26 \pm 0.68 ), proper supervision of the organization on a timely patient visit by the physician (3.12 \pm 0.92$)$, and patient cooperation in pain management (3.21 \pm 0.75$)$, as the main facilitators of pain management, respectively.
\end{abstract}

Conclusion: The establishment of in-service education programs on pain management and strengthening the managerial processes, such as staffing and supervision, can facilitate pain management in hospitalized patients by nurses.

\footnotetext{
* Corresponding Author:

Ismail Azizi-Fini, PhD.

Address: Trauma Nursing Research Center, Kashan University of Medical Sciences, Kashan, Iran

Tel: +98 (912) 2475747

E-mail:azizifinies@yahoo.com
} 


\section{Highlights}

- Pain has been introduced as the fifth vital sign.

- Pain management is among the main tasks of nurses.

- Numerous challenges are correlated with the barriers and facilitators of patient pain management.

\section{Plain Language Summary}

Medicine treats injuries and diseases to support patients and accelerate the healing process. It manages patients' distressing symptoms, like pain, to relieve suffering. The present study assessed Iranian nurses' perspectives on the barriers to and facilitators of pain management. The obtained results revealed that insufficient nurse/patient ratio, excessive demand for pain medications by the patients, the spoken language difference between physician and patient, the ignorance of pain as a priority in care, and failure to precise pain assessment have been respectively determined as the main barriers to pain management by nurses. in the in-service courses of pain management, having sufficient pain management skills, motivation for relieving pain, effective nurse-physician relationship, the proper supervision of the organization on a timely patient visit by physicians, and patient cooperation in pain management were determined as the main facilitators of pain management, respectively.

\section{Introduction}

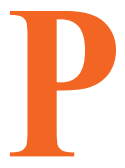

.ain is an unpleasant sensory and emotional experience associated with actual or potential tissue (Ghazanfari, Foroghamari \& Mirhosseini 2011). It is the most frequent reason for seeking healthcare; its effective management is among the top priorities of patient care. One-third of patients referring to the emergency departments (Aflatoonian et al. 2017) and $70 \%$ of patients admitted to hospitals suffer from pain within the first 24 hours of hospitalization (Dehnoalian \& Mohammadpour 2014).

Pain management is considered such an essential part of the care that the American Pain Society coined the phrase "Pain: The 5th Vital Sign" (Oshvandi et al. 2017).

Pain management is a critical interdisciplinary process (Czarnecki et al. 2014) and a significant part of nursing care. Pain management indicates evaluating pain and, if necessary, treating it and may include the use of medication or other methods (Dehnoalian \& Mohammadpour 2014). Proper pain management could lead to short- and long-term recovery, as well as an improved quality of life after surgery. Untreated pain could be associated with future chronic postoperative pain. However, pain management is a difficult task, because patients' pain experiences vary and depend on factors, such as surgery type, the severity and duration of pain, pain medications prescribed, the nurses' knowledge of various postoperative pain management techniques, and patient-related characteristics, such as age, gender, underlying disease, and their psychological state (Oshvandi et al. 2017). Some studies have also reported that pain might be undertreated because of barriers imposed by health professionals, patients, relatives, institutions, and society (Das, Dhar \& Panigrahi).

Considering the widespread prevalence of pain and the difficulty of managing it, it is of great importance to identify the barriers and facilitators associated with pain management. Several studies have investigated the barriers and facilitators correlated with pain management. Furthermore, numerous factors were cited as barriers to pain management. For instance, some studies cited to the nurses' inadequate knowledge of pain management, inadequate nursing staff and their high workload as the major barriers to pain management (Aziznejadroshan, Alhani, \& Mohammadi 2017; Ghazanfari et al. 2011; Twycross 2013). However, other studies reported the physician's insufficient cooperation with nurses (Ghazanfari et al. 2011; Van Niekerk \& Martin, 2003), nurse's indifference, the lack of time for patient education, inappropriate pain relief prescription by the physician, and patients' inadequate cooperation in pain assessment (Ghazanfari et al. 2011), as the crucial barriers to pain management.

A study also recognized inadequate or insufficient doctors' medication orders and delayed access to medica- 
tions, as important barriers to pain management (Czarnecki et al. 2014).

Additionally, studies are inconsistent regarding the facilitators of pain management. It is suggested that a greater number of nurses could be the most significant facilitating factor in pain management (Mohebbi \& Azimzadeh 2014). However, the knowledge of pain physiology, using appropriate pain assessment instruments, the availability of a special pain management guideline, and receiving professional feedback on pain management were among the main facilitators of pain management (Berben et al. 2012). Miller and Abu-Alhaija have also drawn the attention of healthcare providers to the necessity to address cultural issues in pain management (Miller \& Abu-Alhaija 2019a). There are inconsistencies among the studies about the barriers and facilitators associated with pain management in hospitalized patients. Furthermore, there is a difference between the context of care in western countries and Iran. Thus, the present study aimed to investigate the Iranian nurses' perspectives on barriers and facilitators associated with pain management in a large teaching hospital affiliated to Kashan University of Medical Sciences, Kashan City, Iran.

\section{Materials and Methods}

A cross-sectional study was conducted on clinical nurses working in Shahid-Beheshti Hospital of Kashan City, Iran, in 2016. It is a large general teaching hospital affiliated to Kashan University of Medical Sciences and covers a population of $>700000$ individuals with different subcultures. More than 600 nurses with different qualifications are currently working in this hospital; 432 of them have a bachelor's or higher degrees in nursing. Through a census method, all nurses with BA or higher degrees who were eligible ( $N=399)$ were invited to participate in the study; finally, 321 nurses were recruited. The study inclusion criteria included having at least a bachelor's degree in nursing, having a minimum of three months of work experience as a clinical nurse, and a willingness to participate in the study.

A three-part, self-report questionnaire was used for data collection. The researchers designed the instrument through an extensive literature review. The scale's first part comprised questions on nurses' characteristics, such as age, gender, job position, the highest qualification level, a history of clinical work experience, the type of working unit, a history of in-service education related to pain management, the type of working shifts, the extent of interest in the nursing profession, and the number of patients covered in each shift. The second part of the instrument included 26 items on barriers to pain management in the areas of knowledge (1 item), attitude (8 items), professional relationships (4 items), organization (10 items), and patient ( 3 items). The third part of the instrument covered 23 items on the facilitators of pain management in the areas of knowledge (10 items), skills (5 items), attitude (1 item), professional relationships ( 2 items), organization (3 items), and patient ( 2 items). All items are responded on a 5-point Likert-type scale (4: strongly agree; 3: agree; 2: no idea; 1: disagree; \& 0: Strongly disagree.

The scale's validity was assessed by a survey of 10 university professors and approved after submitting their comments. Content Validity Index (CVI) for the items ranged from 0.65 to 1 , and their Content Validity Ratio (CVR) was equal to 0.77 . The inventory's reliability was assessed through the test-retest method with a 10-day interval in a group of 10 nurses who were excluded from the final study sample, and the correlation coefficient was measured to be 0.89 . Cronbach's alpha coefficient of the questionnaire was also calculated as 0.86 .

After obtaining authorization to conduct the study from the Research Deputy of Kashan University of Medical Sciences, and after coordinating with hospital officials, the first author visited all clinical departments of the hospital and recruited the nurses with inclusion criteria. The study purpose was explained to all study participants; then, the study questionnaire was distributed among them to be responded in a quiet environment outside their working shift, and return it to the researcher at a later visit. The researcher provided them with a telephone number to ask their potential questions. The obtained data were analyzed using SPSS software in descriptive statistics.

\section{Results}

Of the 321 distributed questionnaires, 32 and 39 forms were not returned or were answered incompletely, respectively; therefore, they were excluded, and finally, 250 questionnaires were analyzed. The mean age and work experience of the study participants were 32.8 and 9.7 years, respectively. A majority of the study subjects were staff nurses $(91.7 \%)$, and $70.6 \%$ attended no in-service education about pain management. Besides, $48.2 \%$ of the study samples reported a moderate interest in the nursing profession (Table 1).

In the domain of knowledge, the item "the language difference between physician and patient (Mean $\pm \mathrm{SD}$ : $3.01 \pm 0.85)$ "; in the domain of attitude the item "igno- 
Table 1. The demographic characteristics of the study nurses

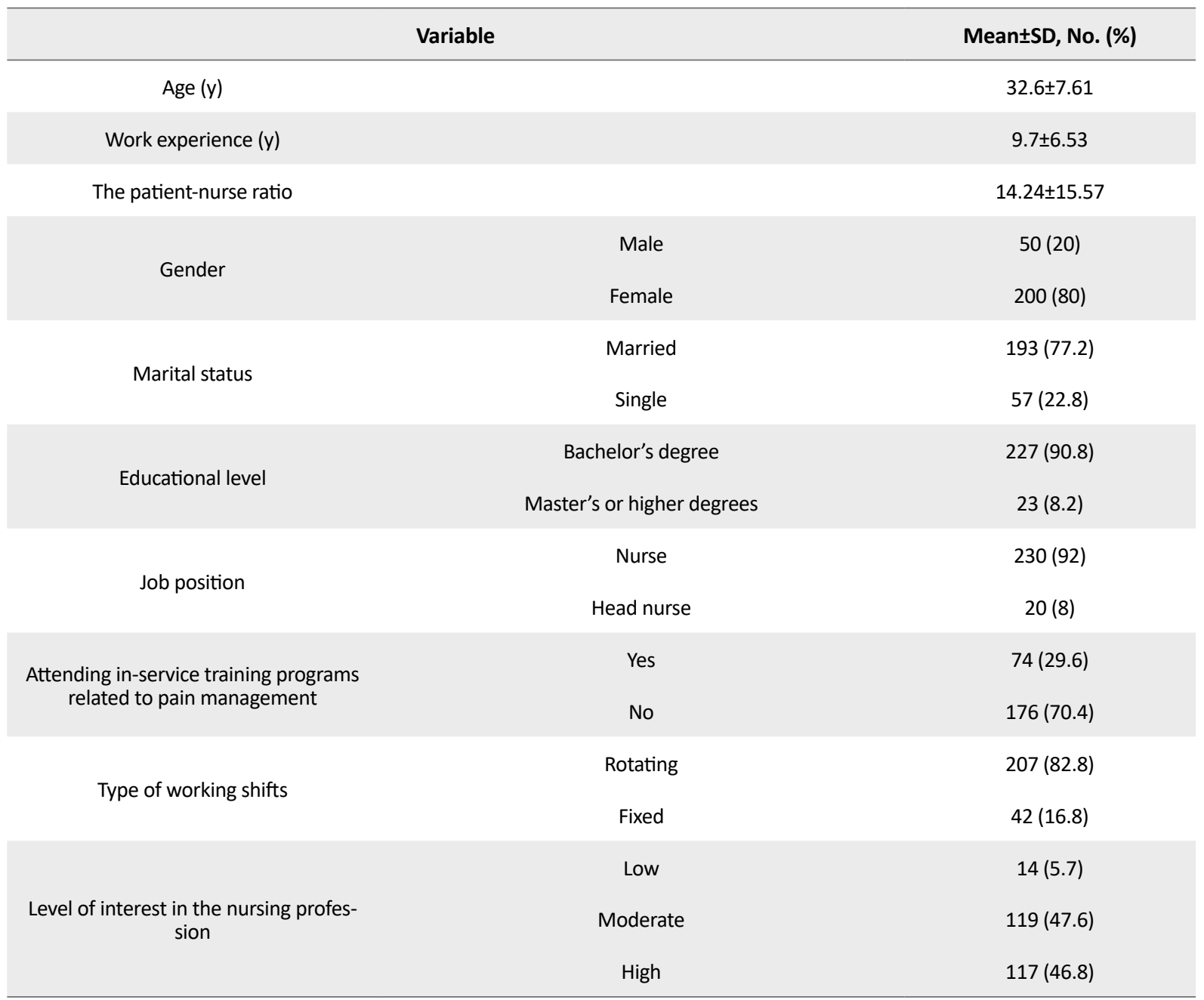

Client- Centered Nursing Care

rance of pain as part of the disease and a priority in care (Mean \pm SD: $2.94 \pm 0.98$ )"; in the domain of inter-professional communication; the item "failure to precise pain assessment (Mean \pm SD: $2.90 \pm 0.89$ )"; in the domain of organization, the item "insufficient nurse/patient ratio (Mean \pm SD: $3.31 \pm 0.87$ )"; and in domain of patient, the item "excessive demand for pain medications by substance-dependent patients (Mean \pm SD: 3.12 \pm 0.95 )" was rated as the main barriers to pain management (Table 2).

In the domain of knowledge, the item "the establishment of in-service courses of pain management (Mean \pm SD: $3.39 \pm 0.63$ )"; in the domain of skills, the item "having sufficient pain management skills (Mean \pm SD: $3.24 \pm 0.76)$ "; In the domain of attitude, the item "nurses' motivation for relieving the patient's pain (Mean \pm SD: $3.24 \pm 0.81)$ "; in the domain of inter-professional relationships, the item "effective nurse-physician relationship (Mean \pm SD: $3.26 \pm 0.68$ )"; in the domain of organization the item "proper supervision of the organization on timely patient visit by the physician (Mean \pm SD: $3.12 \pm 0.92$ )"; and in the domain of patient the item "patient's cooperation in pain management (Mean \pm SD: $3.21 \pm 0.75)$ " were rated as the main facilitators of pain management (Table 3).

\section{Discussion}

According to the studied nurses, the spoken language difference between physician and patient was the main barrier to pain management in the domain of knowledge, while they considered the establishment of in-service pain management courses as the major facilitator of pain management in this domain. These findings indicate a knowledge gap in pain management among physicians and nurses. Addressing the need for in-service education reflects that nurses are aware of their own need for more scientific knowledge on pain management. However, the language barrier between physicians and patients suggested that physicians are not fully aware of the culture 
Table 2. Nurses' perspectives of the most significant barriers to pain management in the domains of knowledge, attitude, interprofessional relationships, organization, and patient

\begin{tabular}{|c|c|c|c|c|c|c|c|}
\hline \multirow[b]{2}{*}{ Priority } & \multirow[b]{2}{*}{ Item } & \multicolumn{5}{|c|}{ No. (\%) } & \multirow[b]{2}{*}{ Mean \pm SD } \\
\hline & & $\begin{array}{l}\text { Strongly } \\
\text { Agre }\end{array}$ & Agree & $\begin{array}{l}\text { I Have } \\
\text { No Idea }\end{array}$ & Disagree & $\begin{array}{l}\text { Strongly } \\
\text { Disagree }\end{array}$ & \\
\hline \multicolumn{8}{|c|}{ Knowledge } \\
\hline 1 & $\begin{array}{l}\text { The language difference between physi- } \\
\text { cian and patient }\end{array}$ & $78(31.5)$ & $106(42.7)$ & $53(21.4)$ & $10(4)$ & $1(0.4)$ & $3.01 \pm 0.85$ \\
\hline \multicolumn{8}{|c|}{ Attitude } \\
\hline 1 & $\begin{array}{l}\text { Ignorance of pain as part of the disease } \\
\text { and a priority in care }\end{array}$ & $75(30.1)$ & $115(46.2)$ & $33(13.3)$ & $20(8)$ & $6(2.4)$ & $2.94 \pm 0.98$ \\
\hline \multicolumn{8}{|c|}{ Inter-professional relationships } \\
\hline 1 & Failure to precise pain assessment & $55(22)$ & $143(57.2)$ & $31(12.4)$ & $15(6)$ & $6(2.4)$ & $2.90 \pm 0.89$ \\
\hline \multicolumn{8}{|c|}{ Organization } \\
\hline 1 & Insufficient nurse/patient ratio & $122(49)$ & $101(40.6)$ & $9(3.6)$ & $14(5.6)$ & $3(1.2)$ & $3.31 \pm 0.87$ \\
\hline \multicolumn{8}{|c|}{ Patient } \\
\hline 1 & $\begin{array}{l}\text { Excessive demand for pain medications by } \\
\text { substance dependent patients }\end{array}$ & $93(39.4)$ & $108(43)$ & $25(9.2)$ & $18(6.8)$ & $4(1.6)$ & $3.12 \pm 0.95$ \\
\hline
\end{tabular}

Client- Centered Nursing Care

and the language of the people they are treating. Both these gaps can profoundly affect the pain management process, especially in pain assessment and evaluating the outcomes of pain-relieving interventions. These data also signify that hospital managers are less concerned about the pain management process. Earlier studies also introduced that nurses' inadequate knowledge and the lack of in-service retraining courses on pain management as the barriers to pain management among inpatients (Alotaibi et al. 2018; Aziznejadroshan et al. 2017; (Berben et al. 2012; Pretorius, Searle \& Marshall, 2015; Spitz et al. 2011; Twycross 2013). A study also reported the inappropriate pain relief prescription by the physician as a barrier to pain management; it highlights a patient-physician language barrier (Ghazanfari et al. 2011). Studies also document that insufficient knowledge of pain

Table 3. Nurses' views of the key facilitators of pain management in the domains of knowledge, skills, attitude, inter-professional relationships, organization, and patient

\begin{tabular}{|c|c|c|c|c|c|c|c|}
\hline \multirow[b]{2}{*}{ Priority } & \multirow[b]{2}{*}{ Facilitators } & \multicolumn{5}{|c|}{ No. (\%) } & \multirow[b]{2}{*}{ Mean $\pm S D$} \\
\hline & & $\begin{array}{l}\text { Strongly } \\
\text { Agree }\end{array}$ & Agree & $\begin{array}{l}\text { I Have No } \\
\text { Idea }\end{array}$ & Disagree & $\begin{array}{l}\text { Strongly } \\
\text { Disagree }\end{array}$ & \\
\hline \multicolumn{8}{|c|}{ Knowledge } \\
\hline 1 & $\begin{array}{l}\text { Attendance in the in-service courses of } \\
\text { pain management }\end{array}$ & $117(46.8)$ & $115(46)$ & $17(6.8)$ & $1(0.4)$ & 0 & $3.39 \pm 0.63$ \\
\hline \multicolumn{8}{|c|}{ Skills } \\
\hline 1 & Having sufficient pain management skills & $101(40.4)$ & $115(46)$ & $27(10.8)$ & $6(2.4)$ & $1(0.4)$ & $3.24 \pm 0.76$ \\
\hline \multicolumn{8}{|c|}{ Attitude } \\
\hline 1 & $\begin{array}{l}\text { Nurses' motivation for relieving the } \\
\text { patient's pain }\end{array}$ & $101(40.4)$ & $\begin{array}{c}124 \\
(49.6)\end{array}$ & $12(4.8)$ & $1(0.4)$ & $3(1.2)$ & $3.24 \pm 0.81$ \\
\hline \multicolumn{8}{|c|}{ Inter-professional relationships } \\
\hline 1 & Effective nurse-physician relationship & $91(36.5)$ & $137(55)$ & $17(6.8)$ & $2(0.8)$ & $2(0.8)$ & $3.26 \pm 0.68$ \\
\hline \multicolumn{8}{|c|}{ Organization } \\
\hline 1 & $\begin{array}{l}\text { Proper supervision of the organization on } \\
\text { a timely patient visit by the physician }\end{array}$ & $97(38.8)$ & $\begin{array}{c}109 \\
(43.6)\end{array}$ & $27(10.8)$ & $12(4.8)$ & $5(2)$ & $3.12 \pm 0.92$ \\
\hline \multicolumn{8}{|c|}{ Patient } \\
\hline 1 & Patient's cooperation in pain management & $90(36.1)$ & $132(53)$ & $17(6.8)$ & $9(3.6)$ & $1(0.4)$ & $3.21 \pm 0.75$ \\
\hline
\end{tabular}


management, the lack of in-service education, and inadequate supervising in this area are among the important factors affecting poor pain management in hospitalized patients (Aziato \& Adejumo 2014). The results of studies in Iran also support this interpretation (Aflatoonian et al. 2017). Kashan is an area comprising different ethnicities and languages; therefore, nurse managers and senior hospital authorities are responsible for establishing and implementing strategies to improve nurses and physicians' basic and cultural knowledge and their attitude regarding pain management (Ucuzal \& Dogan 2015); then, the pain management process might be improved (El-Rahman, Al Kalaldeh \& Muhbes 2013).

Nurses who participated in the present study cited 'having sufficient pain management skills' as an important facilitator of pain management. They used no special instrument for pain assessment and only relied on their subjective interpretations of patients' pain. However, the obtained results indicated that they were aware of the weakness of their practice. Pain assessment and management are essential skills and require special preparations. In this regard, a study reported that nurses' inadequate skill is among the main barriers to pain management (Aziznejadroshan et al. 2017). Some other studies have also pointed to the inadequate skills and inability of nurses for accurate pain assessment (Elcigil et al. 2011; Twycross 2010). A skillful pain assessment requires suitable cognitive preparations and a proper instrument (Ucuzal \& Dogan 2015). Nurse managers should prepare especial pain management protocols and train nurses to use appropriate pain assessment instruments.

In the present study, "ignorance of pain as part of the disease and a priority in care" was considered by the nurses as an attitudinal barrier to pain management. Furthermore, "nurses' motivation for relieving the patient's pain" was considered to be the key facilitator of pain management in the domain of attitude. Nurses have an ethical responsibility to relieve patients' pain and suffering. They must be sensitive to patients' pain and suffering and relieve them with great compassion (Green \& Palpant 2014). A study reported that nurses had a 'strong motivation to ease pain (Blondal \& Halldorsdottir 2009). However, another study reported that nurses' attitude toward pain management is at a moderate level and this affects their motivation for pain management (Aziato \& Adejumo 2014; Mayer et al. 2001).

Moreover, nurses' low motivation is a deterring factor in proper pain management (Parvizi, Alhani \& Aghebati 2008). An individual's motivation to perform a task could be influenced by various variables. Some of these factors are low income, high workload, and inattention of the hospital senior managers to their inappropriate work conditions (Twycross 2013). A study on the barriers of implementing non-pharmacological pain management in children revealed that factors, such as excessive working hours and fatigue, the lack of time, and high workload reduce nurses' motivation to relieve the patients' pain (Mohebbi \& Azimzadeh 2014). By overcoming such barriers and providing a suitable working atmosphere, nurse managers can motivate nurses to pay more attention to their patients' pain and suffering.

The present study findings suggested that nurses perceived the failure to precise pain assessment, as a barrier to pain management in the inter-professional domain; while they perceived the effective nurse-physician relationship, as the key facilitator of pain management in this area. These findings signify the importance of nursepatient-physician relationships in pain management. Previous studies also reported the relationship between physicians, nurses, and patients as a major determinant of the quality of the healthcare practice, including pain management (Aziznejadroshan et al. 2017).

Appropriate pain assessment and management highly depends on appropriate and collaborative relationships between physicians, nurses, and patients. Without it, the nature and the severity of pain cannot be accurately assessed; then, suitable treatment cannot be determined and executed. However, several studies have indicated that poor nurse-patient-physician relationships negatively affected the quality of pain management (Aziznejadroshan et al. 2017; Van Niekerk \& Martin, 2003). Some studies also reported that nurses do not usually discuss pain issues with physicians because of their inappropriate reactions (Clarke et al. 1996; Ucuzal \& Dogan 2015). It has also been reported that the physicians' indifference, the lack of trust in the nursing assessment of pain, and poor nurse-physician relationships are essential barriers to pain management (Elcigil et al. 2011). In addition, some studies have concluded that proper interpersonal communication facilitates patient care and accelerates the recovery process (Spitz et al. 2011).

Proper inter-professional communication in modern healthcare systems plays a determining role in pain management (Miller \& Abu-Alhaija 2019b). Accordingly, all attempts should be made to improve collaborative nursephysician relationships to facilitate better patient and organizational outcomes.

The study results revealed that nurses perceived the insufficient nurse/patient ratio as a barrier to pain man- 
agement in the domain of organization, while they perceived the proper supervision of the organization on a timely patient visit by the physician, as the key facilitator of pain management in this area. Insufficient nurse-patient ration might increase the nurses' workload and decrease the time available for assessing the patients' pain and planning suitable pain reduction strategies.

Regular and timely visits by the physicians could also decrease the time the patient suffers from pain (Twycross 2013). However, the nursing shortage and untimely physicians' visits signify the managerial problems and their effects on the process of pain management. Staffing and supervising employees are among the most critical managerial tasks (Sullivan 2018). In performing their staffing role, the hospital managers should employ a sufficient number of nurses and physicians, and be ensured that they are qualified (Aiken et al. 2018).

Additionally, in performing their supervisory role, they must regularly monitor the performance of their staff (i.e. physicians and nurses) (Tomlinson 2015). However, hospital managers and senior managers in the healthcare system of Iran seem to have shortcomings in their staffing and supervising roles (Tahani 2013). Several studies in Iran reported the irregularity of physicians' visits, the lack of supervision, nurses' inadequate authority in pain medication, inadequate facilities (Dehnoalian \& Mohammadpour 2014; Spitz et al. 2011, the lack of pain committees in hospitals, and the lack of clear policies and protocols for pain management (Mohebbi \& Azimzadeh 2014), as the weaknesses of the healthcare system and barriers to pain management. Perhaps, giving nurses more authority over pain management and prescribing painkillers, along with strengthening the supervision system could compensate the physicians' irregular visits and improve the quality of pain management in patients (Cahyani, Yaputra \& Widyadharma 2018).

The studied nurses cited the item "patient's cooperation in pain management" as the most significant facilitator of pain management in the domain of patient. Successful pain management necessitates close collaboration between patients and nurses. Such collaboration will not only help nurses in assessing the pain and the interventions' outcomes but also help them to plan appropriate patient pain management strategies. Nurses might frequently face patients who are uncooperative with pain assessment and management; this issue might have made them cite this item as an important facilitator. A study has indicated that the patients' lack of awareness of pain medications, and their misconceptions about the addictive effects of some painkillers, are among the factors that interfere with proper pain management (Duignan \& Dunn 2009).
A study also reported the inadequate patient and family participation in pain management as a barrier to non-pharmacologic pain interventions and attributed the problem to the patients' and families' lack of competency and knowledge about such interventions (AziziFini et al. 2012). Providing the patients and their families with the required information could probably help them understand the nature of the care and pain management program; it will consequently increase their cooperation and sense of control over the pain intervention (Aziznejadroshan et al. 2017).

In the present study, "excessive demand for pain medications by substance-dependent patients" was considered by the nurses as a patient-related barrier to pain management. Substance dependence causes patients to seek narcotics, even in the lack of pain, to relieve their substance deprivation syndrome. Such a repeated demand for pain medications may make nurses inattentive to the patient's pain, even when they are in pain (Duignan \& Dunn 2009; Tanabe \& Buschmann 2000).

The current study results could be used to train nursing students and nurses about the concept of pain and pain management. Teaching the nursing students about the frequent associated barriers and facilitators of pain management, and retraining the nurses through in-service education programs on the same issues might improve the nursing students and nurses' knowledge, attitude, and interprofessional communication skills related to pain management. Consequently, the odds of effective pain management in hospitalized patients could increase.

Besides, because some of the barriers and facilitators identified in the present study were different from those of the similar studies in Iran, further multicenter investigations with larger sample sizes are required to fully understand the barriers and facilitators associated with effective pain management in different clinical settings and among nurses working in different subcultures. Accordingly, the quality of pain management and the level of patients' satisfaction with nursing practice could be improved.

Establishing in-service courses in pain management, having sufficient pain management skills, nurses' motivation for relieving the patient's pain, effective nursephysician relationship, the proper organizational supervision on a timely patient visit by the physicians, and patient's cooperation in pain management were identified to be the most significant facilitators of pain management. Therefore, nurse managers and senior hospital authorities should take action to facilitate pain manage- 
ment through appropriate policies and interventions. Nursing managers and hospital authorities should regularly assess the pain management process and reset their strategies according to the target population and related clinical settings.

\section{Ethical Considerations}

\section{Compliance with ethical guidelines}

This study was approved by the Ethics Committee of Kashan University of Medical Sciences (IR.KAUMS. REC1395.167). All of the questionnaires were kept anonymous. All study participants signed an informed consent form attached to the questionnaire, were assured about the confidentiality of their data, and that their participation is voluntary. The researchers respected all of the study participants' rights by the latest version of the Helsinki ethical declaration and verbally acknowledged them about those.

\section{Funding}

This article was supported by the Kashan University of Medical Sciences (Grant No. 95164).

\section{Authors' contributions}

All authors contributed equally in preparing all parts of the research.

\section{Conflict of interest}

The authors declared no conflicts of interest

\section{Acknowledgments}

The researchers would like to thank all the nurses involved in the study, the Vice-chancellor of Research of Kashan University of Medical Sciences, and the hospital authorities for their supports in this study.

\section{References}

Aflatoonian, M. R. et al. 2017. [The survey of nurses, knowledge and attitude towards pain management in Jiroft University of Medical Sciences (Persian)]. Anesthesiology and Pain, 8(2), pp. 14-21.

Aiken, L. H., et al. 2018. Hospital nurse staffing and patient outcomes. Revista Médica Clínica Las Condes, 29(3), pp. 322-7. [DOI:10.1016/j.rmclc.2018.04.011]
Alotaibi, K., et al. 2018. Paediatric pain management: Knowl edge, attitudes, barriers and facilitators among nurses: Integrative review. International Nursing Review, 65(4), pp. 52433. [DOI:10.1111/inr.12465] [PMID]

Aziato, L. \& Adejumo, O., 2014. Determinants of nurses' knowledge gap on pain management in Ghana. Nurse Education in Practice, 14(2), pp. 195-9. [DOI:10.1016/j.nepr.2013.08.004] [PMID]

Azizi-Fini, I., et al. 2012. Correlation between nurses' caring behaviors and patients' satisfaction. Nursing and Midwifery Studies, 1(1), pp. 36-40. [DOI:10.5812/nms.7901]

Aziznejadroshan, P., Alhani, F. \& Mohammadi, E., 2017. Experience of nurses about barriers to pain management in pediatric units: A qualitative study. Journal of Nursing and Midwifery Sciences, 4(3), p. 89. [DOI:10.4103/JNMS.JNMS_2_17]

Berben, S. A., et al. 2012. Facilitators and barriers in pain management for trauma patients in the chain of emergency care. Injury, 43(9), pp. 1397-402. [DOI:10.1016/j.injury.2011.01.029] [PMID]

Blondal, K., \& Halldorsdottir, S., 2009. The challenge of caring for patients in pain: From the nurse's perspective. Journal of Clinical Nursing, 18(20), pp. 2897-906. [DOI:10.1111/j.13652702.2009.02794.x] [PMID]

Cahyani, S. L., Yaputra, F. \& Widyadharma, E., 2018. The nurse' role in pain assessment and management of pediatric patient: A literature review. International Journal of Medical Reviews and Case Reports (Article In Press). [DOI:10.5455/ IJMRCR.role-nurse-pain-pediatric]

Clarke, E. B., et al. 1996. Pain management knowledge, attitudes and clinical practice: The impact of nurses' characteristics and education. Journal of Pain and Symptom Management, 11(1), pp. 18-31. [DOI:10.1016/0885-3924(95)00134-4]

Czarnecki, M. L., et al. 2014. Do barriers to pediatric pain management as perceived by nurses change over time? Pain Management Nursing, 15(1), pp. 292-305. [DOI:10.1016/j. pmn.2012.12.003] [PMID]

Das, S. K., Dhar, S. S. \& Panigrahi, A., 2019. Prevalence of pain and its characteristics in hospitalized patients in an indian teaching hospital. Pain Management Nursing, pii: S15249042(18), pp. 30409-0. [DOI:10.1016/j.pmn.2019.06.005] [PMID]

Dehnoalian, A. \& Mohammadpour, A., 2014. [Barriers to pain management: Comparing the viewpoints between physicians and nurses (Persian)]. Anesthesiology and Pain, 5(2), pp. 49-56.

Duignan, M., \& Dunn, V., 2009. Perceived barriers to pain management. Emergency Nurse, 16(9), pp. 31-5. [DOI:10.7748/ en2009.02.16.9.31.c6848] [PMID]

Elcigil, A., et al. 2011. Nurses' perceived barriers to assessment and management of pain in a university hospital. Journal of Pediatric Hematology/Oncology, 33, pp. S33-8. [DOI:10.1097/ MPH.0b013e3182121bef] [PMID]

El-Rahman, M. A., Al Kalaldeh, M. T. \& Muhbes, F. J., 2013. Knowledge and attitude towards pain management: A comparison between oncology and non-oncology nurses in Jordan. International Journal of Advanced Nursing Studies, 2(2), p. 95. [DOI:10.14419/ijans.v2i2.1006] 
Ghazanfari, Z., Foroghamari, G., \& Mirhosseini, M., 2011. [The nursing staff view about barriers of using pain relief methods (Persian)]. Iranian Journal of Critical Care Nursing, 3(4), pp. 14952.

Green, R. M. \& Palpant, N. J., 2014. Suffering and bioethics. Oxford: Oxford University Press. [DOI:10.1093/acprof:o so/9780199926176.001.0001]

Mayer, D. M., et al. 2001. Speaking the language of pain. American Journal of Nursing, 101(2), pp. 44-9. [DOI:10.1097/00000446200102000-00047] [PMID]

Miller, E. T. \& Abu-Alhaija, D. M., 2019a. Cultural influences on pain perception and management. Pain Management Nursing, 20(3), pp. 183-4. [DOI:10.1016/j.pmn.2019.04.006] [PMID]

Miller, E. T. \& Abu-Alhaija, D. M., 2019b. Importance of interdisciplinary pain management. Pain Management Nursing, 20(2), pp. 91-2. [DOI:10.1016/j.pmn.2019.02.001] [PMID]

Mohebbi, P. \& Azimzadeh, R., 2014. [Barrier of implementing non-pharmacological pain management in children and presented intereventions by nurses (Persian)]. Journal of Holistic Nursing and Midwifery, 24(2), pp. 40-8.

Oshvandi, Kh., et al. 2017. [Effect of pain management training on knowledge, attitude and pian relief methods of recovery nurses (Persian)]. Journal of Nursing Education, 6(4), pp. 11-8.

Parvizi, F., Alhani, F., \& Aghebati, N., 2008. [The nurses' problems in applying non-pharmacological pain management for children (Persian)]. Iranian Journal of Nursing Research, 3(9), pp. 85-92.

Pretorius, A., Searle, J. \& Marshall, B., 2015. Barriers and enablers to emergency department nurses' management of patients' pain. Pain Management Nursing, 16(3), pp. 372-9. [DOI:10.1016/j.pmn.2014.08.015] [PMID]

Spitz, A., et al. 2011. Primary care providers' perspective on prescribing opioids to older adults with chronic noncancer pain: A qualitative study. BMC Geriatrics, 11, p. 35. [DOI:10.1186/1471-2318-11-35] [PMID] [PMCID]

Sullivan, E., 2018. Effective leadership and management in nursing ( $9^{\text {th }}$ Edition). New York: Pearson.

Tahani, B., 2013. Stewardship of national oral health system in Iran: Its strengths and weaknesses. Archives of Iranian Medicine, 16(12), pp. 717-24.

Tanabe, P. \& Buschmann, M., 2000. Emergency nurses' knowledge of pain management principles. Journal of Emergency Nursing, 26(4), pp. 299-305. [DOI:10.1016/S00991767(05)80053-4] [PMID]

Tomlinson, J., 2015. Using clinical supervision to improve the quality and safety of patient care: A response to Berwick and Francis. BMC Medical Education, 15(1), p. 103. [DOI:10.1186/ s12909-015-0324-3] [PMID] [PMCID]

Twycross, A., 2010. Managing pain in children: Where to from here? Journal of Clinical Nursing, 19(15-16), pp. 2090-9. [DOI:10.1111/j.1365-2702.2010.03271.x] [PMID]

Twycross, A., 2013. Nurses' views about the barriers and facilitators to effective management of pediatric pain. Pain Management Nursing, 14(4), pp. e164-72. [DOI:10.1016/j. pmn.2011.10.007] [PMID]
Ucuzal, M. \& Dogan, R., 2015. Emergency nurses' knowledge, attitude and clinical decision making skills about pain. International Emergency Nursing, 23(2), pp. 75-80. [DOI:10.1016/j. ienj.2014.11.006] [PMID]

Van Niekerk, L. M. \& Martin, F., 2003. The impact of the nursephysician relationship on barriers encountered by nurses during pain management. Pain Management Nursing, 4(1), pp. 3-10. [DOI:10.1053/jpmn.2003.4] [PMID] 
This Page Intentionally Left Blank 